\title{
Intake of antioxidant vitamins in women with different physical activity levels
}

\author{
Anna Pietrzak $^{1}$, Anna Kęska ${ }^{1}$, Marziyeh Saghebjoo², Zeynab Nezamdoost ${ }^{2}$ \\ ${ }^{1}$ Department of Biochemistry and Biology, Józef Piłsudski University of Physical Education, Warsaw, Poland; ${ }^{2}$ Department \\ of Exercise Physiology, Faculty of Sport Sciences, University of Birjand, Birjand, Iran
}

\section{Summary}

Study aim: The purpose of this study was to compare intake of antioxidant vitamins (A, C, E) in young women with various levels of physical activity.

Material and methods: The study included 3 groups of females: 40 women with no extra physical activity (Sedentary), 40 women involved in regular, moderate sports activities (Recreationally Active) and 40 female athletes competing at an international level (Athletes). Participants' diet was assessed on the basis of 3-day diet records which were analysed using the computer program 'Dieta 5.0'. Body composition was evaluated by the bioelectrical impedance analysis (BIA) method.

Results: Athletes were characterized by the lowest body fat and highest lean body mass in comparison with the other groups. They also showed the highest intake of energy, proteins and carbohydrates compared to Active and Sedentary women. The consumption of vitamin A amounted to $180.0 \%$ of RDA in Athletes, $98.8 \%$ in Recreationally Active and $97.8 \%$ in Sedentary women. Vitamin C intake in Athletes equalled $275.0 \%$ of RDA, whereas the deficiency of this vitamin was observed in Recreationally Active and Sedentary women (62.3\% and $46.1 \%$ of RDA, respectively). The study groups showed consumption of vitamin E at the level of $146.7 \%$ of AI in Athletes, $115.0 \%$ in Recreationally Active and $111.3 \%$ in Sedentary women.

Conclusion: Athletes consumed excessive amounts of antioxidant vitamins. Recreationally Active and Sedentary women met the demand for vitamin A and E, but the intake of vitamin $\mathrm{C}$ was not sufficient, which could lead to health problems. The current findings also indicate that energy intake was at a low level regardless of the study group.

\section{Keywords: Women - Physical activity - Antioxidant vitamins - Diet - Oxidative stress}

\section{Introduction}

Regular and moderate physical activity has a positive effect on the human body by reducing the risk of many diseases (e.g. osteoporosis, diabetes, cancer, obesity, depression) [19]. On the other hand, it has been well documented that high performance athletes are exposed to a number of negative effects of strenuous physical activity such as intensified catabolic reactions, subsequent disruption of homeostasis and also oxidative stress [35]. The occurrence of oxidative stress results from the imbalance between production of reactive oxygen species (ROS) and adequate antioxidant defence [23]. Reactive oxygen species are a natural product of cell metabolism. They are produced during aerobic processes (e.g. during the respiratory chain in mitochondria). One of the factors increasing the production of ROS is physical activity, during which oxygen uptake increases 10-15 times with respect to the resting state [14]. In normal concentrations ROS act as regulators of different processes (e.g. stimulating the transport of glucose into cells, increasing permeability of capillary walls), but their profuse production can contribute to the oxidation of proteins, lipids and DNA, resulting in tissue damage [40, 41]. Many pathological body states and ailments such as cardiovascular and neurological diseases or cancer are related to ROS [26, 29].

Negative effects of ROS, under normal physiological conditions, are removed by the cellular antioxidant system consisting of endogenous and exogenous antioxidants [9, 31]. Vitamins A, C, E are components of the exogenous group [2]. Vitamin A is a collective name for compounds of the retinoid group (the most important is retinol) and provitamins (alpha and beta carotene). The main task of vitamin $\mathrm{A}$ is to stimulate red bone marrow, 
improve eyesight and accelerate wound healing. It participates in biochemical processes in muscles and stimulates the adrenal cortex, which can be useful in physical activity. It may also help reduce inflammatory processes and oxidative stress during exercise [6]. Vitamin $\mathrm{C}$ (ascorbic acid) first of all is involved in the formation and maintenance of collagen, cartilage, bones, blood vessels and has anti-tumour effects. In addition, this vitamin is a strong reducing agent thanks to its electron donating properties. It can inactivate a variety of reactive species and minimize damage to body tissues [12]. Similarly to vitamin $\mathrm{C}$, vitamin $\mathrm{E}$ is an important antioxidant. Due to its capacity for scavenging ROS, it exerts the main function of protecting cellular membranes and plasma lipoproteins against lipid peroxidation [9]. During physical activity it can contribute to the reduction of oxygen dept, protection of red blood cells and maintenance of adequate membrane permeability [11]. Thus, a sufficient intake of aforementioned vitamins through a varied and balanced diet can compensate for the harmful effects of ROS [14].

It has been well documented that physically active people, especially women, often experience deficiency of many nutrients. They may have difficulties in maintaining an adequate nutritional status due to improper diet and/ or their increased energy and micronutrients loss related to excessive physical effort [17]. However, it should be underlined that most of the existing studies focus mainly on energy deficits in competitive sportsmen, whereas a considerably smaller number describe deficiencies of vitamins and minerals linked to recreational physical activity. Meanwhile, deficit of these components in the body, especially shortage of antioxidant vitamins, can result in increased accumulation of ROS in muscles, contributing to their pain and raised risk of injury [5]. Insufficiency of these vitamins may also strengthen the feeling of overtraining or even disturb the processes of regeneration by affecting the metabolism of carbohydrates and proteins [13]. Thus, this study was undertaken to evaluate the intake of antioxidant vitamins in three groups of women with different levels of physical activity - high performance, recreationally active and sedentary.

\section{Materials and methods}

\section{Subjects}

Recruited woman were volunteers. Each participant was assigned to one of three groups on the basis of their physical activity level: women not engaged in any physical activity were classified as Sedentary $(n=40)$. The Recreationally Active women group consisted of subjects involved in regular, moderate physical activity (students of physical education; the duration of physical activity ranged from three to seven hours/week). The women Athletes group comprised females professionally engaged in sports (combat, endurance and strength disciplines), competing at an international level (the duration of physical activity was over seven hours/week). Each group was made up of 40 women aged 18 to 31 .

The study subjects were informed about the purpose and procedures of the research and provided their written consent.

\section{Anthropometric measurements}

The weight was measured to the nearest $0.5 \mathrm{~kg}$ and height to the nearest $0.5 \mathrm{~cm}$ using standard medical equipment. The body mass index (BMI) was calculated from the formula weight $(\mathrm{kg}) /$ height $^{2}(\mathrm{~m})$. Lean body mass and body fat were assessed with bioelectrical impedance analysis (BIA) using BC-418 equipment (Tanita Co., Japan). All the measurements were taken on the same morning with the subjects wearing sports outfits without shoes.

\section{Daily energy, macronutrients and vitamins intake}

The total energy, macronutrients and vitamins intake was assessed as self-reported using a nutrition diary recorded and provided by each participant instructed before the study. Dietary information contained all the foods, meals, drinks and supplements consumed over 3 days. Diet information was validated by a trained interviewer who established the exact size of meals using a set of pictures of meals and foods [34]. Diet composition was analysed using the computer program 'Dieta 5.0' purchased from the Institute of Food and Nutrition in Warsaw (Poland).

The recommendations of the Institute of Food and Nutrition were considered for diet evaluation in Recreationally Active and Sedentary women [11], while Athletes' diet was assessed using the guidelines of the International Society of Sport Nutrition [13].

Usual daily intake of energy, proteins, carbohydrates, fats and vitamins A, C, E, was estimated. Diet energy values were evaluated using the Estimated Average Requirement (EAR) norm. The Recommended Dietary Allowances (RDA) level was used to assess the consumption of proteins, carbohydrates, fats, and vitamins $\mathrm{A}$ and $\mathrm{C}$, and the Adequate Intake (AI) norm for vitamin E.

\section{Statistical analysis}

All variables were checked for normality using the Shapiro-Wilk test. The statistical significance of the differences between three groups was assessed using KruskalWallis ANOVA. Data are presented as mean $\pm \mathrm{SD}$. $\mathrm{P}<0.05$ was considered significant. All calculations were carried out using Statistica v.10. (StatSoft, USA). 


\section{Results}

Subjects' characteristics are shown in Table 1. There were no significant differences between groups in body weight, height and BMI. A difference was found in body fat $(\mathrm{kg}, \%)$. Athletes were characterized by the lowest body fat in kilograms and percent in comparison with the other groups ( $p<0.001)$, whereas the highest values of these parameters were observed in Sedentary women. There was also a significant difference between the groups in lean body mass (LBM) $(\mathrm{p}<0.001)$.

Athletes showed the highest energy intake in comparison with Active and Sedentary women (Table 2) $(p<0.001)$. However, the highest percent of subjects with adequate energy consumption regarding energy recommendations was observed in Sedentary women (although the difference was not statistically significant). There were no differences between the groups in the percent of participants whose energy intake was very low, i.e. below $30 \mathrm{kcal} / \mathrm{LBM}$.

Significant differences were found in proteins and carbohydrates intake in grams, percent and grams per body mass between Athletes and the other groups $(\mathrm{p}<0.001)$. As far as fat intake was concerned, the only observed difference regarded the percent of fat content in the diet.

The amounts of vitamins intake are shown in Table 3. There was a difference in the consumption of every vitamin between Athletes and the other groups $(p<0.001)$. Athletes were characterized by the highest intake of those

Table 1. Anthropometric characteristics of the participants (mean $\pm \mathrm{SD}$ )

\begin{tabular}{|c|c|c|c|}
\hline & Athletes $(n=40)$ & Recreationally Active $(\mathrm{n}=40)$ & Sedentary $(n=40)$ \\
\hline Age [years] & $25.6 \pm 2.5$ & $20.9 \pm 1.2$ & $21.3 \pm 1.5$ \\
\hline Height $[\mathrm{m}]$ & $1.68 \pm 0.06$ & $1.69 \pm 0.07$ & $1.68 \pm 0.06$ \\
\hline Body mass $[\mathrm{kg}]$ & $62.0 \pm 7.0$ & $62.0 \pm 7.2$ & $61.1 \pm 8.0$ \\
\hline BMI* & $20.0 \pm 2.3$ & $21.4 \pm 2.1$ & $21.8 \pm 2.8$ \\
\hline Body fat $[\%]$ & $20.4 \pm 2.3^{\mathrm{a}}$ & $22.4 \pm 4.0^{\mathrm{a}}$ & $31.2 \pm 6.7$ \\
\hline Body fat $[\mathrm{kg}]$ & $12.8 \pm 2.8^{\mathrm{a}}$ & $13.9 \pm 3.3^{\mathrm{a}}$ & $19.2 \pm 5.2$ \\
\hline $\mathrm{LBM}[\mathrm{kg}]^{\wedge}$ & $49.1 \pm 5.6^{\mathrm{a}, \mathrm{b}}$ & $48.1 \pm 5.2^{\mathrm{c}}$ & $41.9 \pm 5.9$ \\
\hline
\end{tabular}

*BMI - Body Mass Index; ${ }^{\wedge}$ LBM - Lean Body Mass; ${ }^{\mathrm{a}}-\mathrm{p}<0.001$ significantly different vs. Sedentary women; ${ }^{\mathrm{b}}-\mathrm{p}<0.05$ significantly different vs. Active women; ${ }^{\mathrm{c}}-\mathrm{p}<0.005$ significantly different vs. Sedentary women.

Table 2. Daily energy and macronutrient intake (mean \pm SD)

\begin{tabular}{|c|c|c|c|}
\hline & Athletes $(n=40)$ & Recreationally Active $(\mathrm{n}=40)$ & Sedentary $(n=40)$ \\
\hline Energy intake [kcal] & $2171.7 \pm 357.9^{\mathrm{a}, \mathrm{b}}$ & $1662.5 \pm 556.2$ & $1691.1 \pm 448.8$ \\
\hline Energy demand [\%] & 69.6 & 67.4 & $84.0^{\wedge}$ \\
\hline <30kcal/LBM [\%] & 33 & 30 & 20 \\
\hline Protein $[\mathrm{g} / \mathrm{kg} \mathrm{bm}]$ & $1.6 \pm 0.7^{\mathrm{a}, \mathrm{b}}$ & $1.0 \pm 0.4$ & $1.0 \pm 0.4$ \\
\hline Protein $[\mathrm{g}]$ & $99.2 \pm 44.2^{\mathrm{a}, \mathrm{b}}$ & $60.8 \pm 19.7$ & $57.1 \pm 18.9$ \\
\hline Protein $[\%]$ & $18.2 \pm 7.5^{\mathrm{c}}$ & $15.1 \pm 2.2^{\mathrm{c}}$ & $13.7 \pm 2.7$ \\
\hline Carbohydrates $[\mathrm{g} / \mathrm{kg} \mathrm{bm}]$ & $4.8 \pm 1.4^{\mathrm{a}, \mathrm{c}}$ & $3.7 \pm 1.3$ & $3.8 \pm 1.1$ \\
\hline Carbohydrates $[\mathrm{g}]$ & $293.6 \pm 84.8^{\mathrm{a}, \mathrm{b}}$ & $215.2 \pm 3.7$ & $230.5 \pm 63.8$ \\
\hline Carbohydrates [\%] & $53.7 \pm 11.8^{\mathrm{d}}$ & $49.0 \pm 6.1$ & $52.1 \pm 7.0$ \\
\hline Fat $[\mathrm{g} / \mathrm{kg} \mathrm{bm}]$ & $1.1 \pm 0.5$ & $1.2 \pm 0.5$ & $1.1 \pm 0.4$ \\
\hline Fat $[\mathrm{g}]$ & $68.5 \pm 28.3$ & $67.7 \pm 25.1$ & $65.6 \pm 22.0$ \\
\hline Fat $[\%]$ & $28.1 \pm 8.7^{\mathrm{a}, \mathrm{b}}$ & $35.8 \pm 5.4$ & $34.1 \pm 5.5$ \\
\hline
\end{tabular}

${ }^{a}-p<0.001$ significantly different vs. Active women; ${ }^{b}-p<0.001$ significantly different vs. Sedentary woman; ${ }^{c}-p<0.01$ significantly different vs. Sedentary women; ${ }^{\mathrm{d}}-\mathrm{p}<0.05$ significantly different vs. Active women; ${ }^{\wedge}-\mathrm{p}<0.1$ tendency towards significance. 
Table 3. Daily vitamins intake (mean \pm SD)

\begin{tabular}{lccc}
\hline & Athletes $(\mathrm{n}=40)$ & Recreationally Active $(\mathrm{n}=40)$ & Sedentary $(\mathrm{n}=40)$ \\
\hline Vitamin A $[\mu \mathrm{g}]$ & $1265.5 \pm 489.0^{\mathrm{a}, \mathrm{b}}$ & $691.8 \pm 437.8$ & $684.6 \pm 492.5$ \\
Beta-carotene $[\mu \mathrm{g}]$ & $3221.8 \pm 2267.5^{\mathrm{b}, \mathrm{c}}$ & $2085.7 \pm 1883.4$ & $2097.7 \pm 2621.8$ \\
Retinol $[\mu \mathrm{g}]$ & $453.6 \pm 161.9^{\mathrm{a}, \mathrm{b}}$ & $341.4 \pm 201.1$ & $332.1 \pm 194.6$ \\
Vitamin C $[\mathrm{mg}]$ & $206.3 \pm 105.4^{\mathrm{a}, \mathrm{b}}$ & $46.7 \pm 27.8$ & $34.6 \pm 31.1$ \\
Vitamin E $[\mathrm{mg}]$ & $22.2 \pm 16.9^{\mathrm{a}, \mathrm{b}}$ & $9.2 \pm 3.9$ & $8.9 \pm 4.0$ \\
\hline
\end{tabular}

a $-\mathrm{p}<0.001$ significantly different vs. Active women; ${ }^{\mathrm{b}}-\mathrm{p}<0.001$ significantly different vs. Sedentary women; ${ }^{\mathrm{c}}-\mathrm{p}<0.01$ significantly different vs. Active women.

Table 4. Macronutrient and vitamins intake per $1000 \mathrm{kcal}$

\begin{tabular}{lccc}
\hline & Athletes $(\mathrm{n}=40)$ & Recreationally Active $(\mathrm{n}=40)$ & Sedentary $(\mathrm{n}=40)$ \\
\hline Protein/1000 [g/kcal] & $45.8 \pm 18.9^{\mathrm{a}}$ & $37.1 \pm 5.5^{\mathrm{b}}$ & $33.8 \pm 6.5$ \\
Carbohydrates/1000 [g/kcal] & $135.5 \pm 30.4$ & $129.6 \pm 15.4$ & $136.6 \pm 17.7$ \\
Fat/1000 [g/kcal] & $31.4 \pm 9.7^{\mathrm{c}, \mathrm{d}}$ & $40.5 \pm 6.1$ & $38.6 \pm 6.3$ \\
Vitamin A/1000 $[\mu \mathrm{g} / \mathrm{kcal}]$ & $591.4 \pm 236.5^{\mathrm{d}, \mathrm{e}}$ & $414.4 \pm 207.7$ & $403.8 \pm 277.3$ \\
Beta-carotene $/ 1000[\mu \mathrm{g} / \mathrm{kcal}]$ & $1422.3 \pm 795.3^{\mathrm{a}}$ & $1240.3 \pm 999.3$ & $1219.3 \pm 1471.0$ \\
Retinol $/ 1000[\mu \mathrm{g} / \mathrm{kcal}]$ & $207.2 \pm 60.1$ & $205.9 \pm 87.6$ & $199.0 \pm 125.0$ \\
Vitamin C/1000 $[\mathrm{mg} / \mathrm{kcal}]$ & $96.7 \pm 50.9^{\mathrm{c}, \mathrm{d}}$ & $27.9 \pm 14.3$ & $19.7 \pm 15.6$ \\
Vitamin E/1000 $[\mathrm{mg} / \mathrm{kcal}]$ & $10.1 \pm 7.1^{\mathrm{c}, \mathrm{d}}$ & $5.5 \pm 1.8$ & $5.2 \pm 1.6$ \\
\hline
\end{tabular}

${ }^{a}-p<0.01$ significantly different vs. Sedentary women; ${ }^{b}-p<0.05$ significantly different vs. Sedentary women; ${ }^{c}-p<0.001$ significantly different vs. Active women; ${ }^{d}-p<0.001$ significantly different vs. Sedentary women; ${ }^{\mathrm{e}}-\mathrm{p}<0.01$ significantly different vs. Active women

vitamins. However, there were no significant differences in vitamins intake found in the groups of Recreationally Active and Sedentary women.

Table 4 shows macronutrients and vitamins intake per $1,000 \mathrm{kcal}$ consumed. No differences in carbohydrates and retinol intake were observed in the study participants. Sedentary women displayed the highest intake of carbohydrates and the lowest one of proteins, but a reverse intake of those macronutrients was observed in the group of Recreationally Active women.

\section{Discussion}

The present study showed that daily food intake in all the tested female groups was definitely lower than their energy demand. Athletes consumed the amount of energy recommended for a population with low physical activity. Recreationally Active and Sedentary women had a similar, low calorie intake comparable with the recommendations for bed-ridden patients [11]. Moreover, according to the literature, providing less than $30 \mathrm{kcal}$ per $1 \mathrm{~kg}$ of lean body mass (LBM) is dangerous to health [15]. It is worth stressing that in each group individuals with such low energy consumption constituted a considerable percentage of the group (20\%-33\%).

Comparing our results with the available data, it can be seen that negative energy balance in athletes is widespread, regardless of their type of sports disciplines, level of competition or training periodization [32]. It can be caused by heavy or intense workouts and poorly balanced diet. One should emphasize that long-term energy deficiency in women can result in various health disorders such as menstrual problems or diminished bone density [33]. Additionally, it increases the risk of injury in sportswomen, and reduces their concentration and ability to cope with pressure, which all directly affect the quality of competition [18]. Surprisingly, we also observed low energy intake in women with moderate and low physical activity. It is probably associated with the current trend among women 
wishing to have a very slim body. Moreover, like in the women Athletes, constant energy deficit in both of these groups may also contribute to hormonal problems [10].

No statistically significant differences were observed in the intake of all macronutrients between the groups of Recreationally Active and Sedentary women. It was also found that their diet composition was in line with the recommendations for the Polish population. In contrast, the group of Athletes was characterized by a low intake of carbohydrates, which is inconsistent with the latest recommendations for sportspeople [24, 38]. The observed insufficient intake of this macronutrient in athletes could be related to the attempts of losing weight, which are an integral part of some sports disciplines (e.g. combat sports, bodybuilding) $[8,25]$. Protein intake in Athletes ( $\mathrm{g} / \mathrm{kg}$ body mass) complied with the recommendations for sportspeople but was not similar to the results of other authors who reported lower protein intake $[32,36]$. It can be explained by the fact that the group of Athletes consisted of representatives of strength sport disciplines, which are usually characterized by high consumption of this macronutrient [3].

The intake of vitamin A in the present study amounted to $180.0 \%$ of RDA in Athletes, $98.8 \%$ in Recreationally Active and $97.8 \%$ in Sedentary women [11, 13]. Although women from the Recreationally Active and Sedentary groups did not meet the energy demand, they were provided with the recommended amount of this vitamin in their diet. In Athletes the supply of vitamin A was twice as large as in the other study groups, despite insufficient energy consumption. Other authors also report excessive intake of this vitamin in sportspeople or people with moderate physical activity $[21,22]$. It may be due to the fact that vitamin $\mathrm{A}$ and its derivatives occur in a large number of vegetable and animal food products. It should be stressed that excessive and prolonged supply of this vitamin can be hepatotoxic, may cause bone or joint pain, headaches, gastro-intestinal disorders and skin lesions [30].

The study found that vitamin $\mathrm{C}$ intake was very high in Athletes and was equal to $275.0 \%$ of RDA. On the other hand, a deficiency of this vitamin was observed in the groups of Recreationally Active and Sedentary women (62.3\% of RDA and $46.1 \%$ of RDA, respectively). Very high consumption of vitamin $C$ in sportspeople may be due to the use of supplements, which can contain extra quantities of vitamins. Other data showed that athletes often use supplements of this vitamin, despite the fact that it is not clear if vitamin $\mathrm{C}$ supplementation is necessary and good for health, or if it helps during physical activity $[16,20]$. What is more, it was shown that a high dose of ascorbic acid $(>2,000 \mathrm{mg} / \mathrm{d})$ can lead to kidney stones and gastrointestinal disorders [39]. The results of our study are in line with other authors, who also reported low intake of vitamin C in people without extra physical activity, explaining it by an insufficient amount of fruit and vegetables in the diet [1]. We should be reminded at this point that vitamin C deficiency may adversely affect health (e.g. scurvy, cataract, atherosclerosis) [4, 37].

The last antioxidant measured in this study was vitamin E. The study groups showed its consumption at the level of $146.7 \%$ of AI in Athletes, $115.0 \%$ in Recreationally Active and $111.3 \%$ in Sedentary women, so all the groups met the recommended demand. However, a very high dose of vitamin $\mathrm{E}(>1,000 \mathrm{mg} / \mathrm{d})$ can cause muscle weakness, headache and fatigue. The results of other studies showing consumption of this vitamin in athletes are ambiguous. There can be found data in which intake of vitamin E was either at a high or insufficient level [27]. This can be explained by the fact that the study authors may use different recommendations for athletes. Regarding people with low or moderate psychical activity, other authors also reported adequate intake of vitamin $\mathrm{E}[7,28]$. It was documented that deficits of this vitamin are very rare and usually associated with various diseases (e.g. cystic fibrosis, BassenKornzweig syndrome) [37].

\section{Conclusion}

The present study is among the few that present the intake of antioxidant vitamins in Polish athletes. We observed that athletes consume high doses of antioxidant vitamins not only in total intake but also in intake per 1,000 calories. The main reason for that is better knowledge about nutrition in sportspeople. On the other hand, it may also be due to consuming more food designed for athletes (e.g. drinks, bars, meal replacements, etc.) which contains more vitamins, or by using supplements (e.g. creatine) which have no nutritional value but contain extra doses of vitamins. The conducted study also showed that in recreationally active and sedentary women the consumption of vitamins $\mathrm{A}$ and $\mathrm{E}$ was in line with the recommendations, while vitamin $\mathrm{C}$ intake was far below the norm. It proves inappropriate diet composition in the studied female groups and indicates the necessity for effective nutritional education. Additionally, we found a tendency towards a low calorie diet, not only in women engaged in high but also moderate or low levels of physical activity, and such a tendency can bring about adverse health consequences.

Conflict of interest: Authors state no conflict of interest.

\section{References}

1. Beydoun M.A., Fanelli Kuczmarski M., Kitner-Triolo M.H., Beydoun H.A., Kaufman J.S., Mason M.A., Evans M.K., Zonderman A.B. (2015) Dietary antioxidants intake and its association with cognitive function 
in an ethnically diverse sample of US adults. Psychosom. Med., 77(1): 68-82.

2. Bouayed J., Bohn T. (2010) Exogenous antioxidants - Double-edged swords in cellular redox state: Health beneficial effects at physiologic doses versus deleterious effects at high doses. Oxid. Med. Cell. Longev., 3(4): 228-237.

3. Burke L.M., Hawley J.A., Wong S.H, Jeukendrup A.E. (2011) Carbohydrates for training and competition. J. Sports Sci., 29(1): 17-27.

4. Childs A., Jacobs C., Kaminski T.,Halliwell B., Leeuwenburgh C. (2001) Supplementation with vitamin C and $\mathrm{N}$-acetylcysteine increases oxidative stress in humans after an acute muscle injury induced by eccentric exercise. Free Radical Bio. Med., 31(6): 745-753.

5. Close G.L., Ashton T., McArdle A., Maclaren D.P.M, (2005) The emerging role of free radicals in delayed onset muscle soreness and contraction-induced muscle injury. Comp. Biochem. Physiol. A Mol. Integr. Physiol., 142(3): 257-266.

6. Curhan S.G, Stankovic K.M., Eavey R.D., Wang M., Stampfer M.J., Curhan G.C. (2015) Carotenoids, vitamin A, vitamin $C$, vitamin $\mathrm{E}$, and folate and risk of self-reported hearing loss in women. Am. J. Clin. Nutr., 102(5): 1167-1175.

7. Dickinson A., MacKay D. (2014) Health habits and other characteristics of dietary supplement user: a review. Nutr. J., 13: 14.

8. Franchini E., Brito C.J., Artioli G.G. (2012) Weight loss in combat sports: physiological, psychological and performance effects. J. Int. Soc. Sport Nutr., 9: 52-58.

9. Gomes E.C., Silva A.N., de Oliveira M.R. (2012) Oxidants, antioxidants, and the beneficial roles of exerciseinduced production of reactive species. Oxid. Med. Cell. Longev., DOI: 10.1155/2012/756132.

10. Hagobian T.A., Sharoff C.G., Stephens B.R., Wade G.N., Silva J.E., Chipkin S.R., Braun B. (2009) Effects of exercise on energy-regulating hormones and appetite in men and women. Am. J. Physiol. Regul. Integr. Comp. Physiol., 296: 233-242.

11. Jarosz M. Normy żywienia dla populacji polskiej nowelizacja. Warszawa: Instytut Żywności i Żywienia; 2012.

12. Kook S-Y., Lee K-M., Kim Y., Cha M-Y., Kang S., Baik S.H., Lee H., Park R., Mook-Jung I. (2014) Highdose of vitamin $\mathrm{C}$ supplementation reduces amyloid plaque burden and ameliorates pathological changes in the brain of 5XFAD mice. Cell Death Dis., 5(2): e1083.

13. Kreider R.B., Wilborn C.D. Tayler L., et al. (2010) ISSN exercise and sport nutrition review: research and recommendations. J. Int. Soc. Sport Nutr., 7: 7.

14. Kurkcu R. (2010) The effects of short-term exercise on the parameters of oxidant and antioxidant system in handball players. Afr. J. Pharm. Pharmacol., 4(7): 448-452.
15. Loucks A.B., Thuma J.R. (2003) Luteinizing hormone pulsatility is disrupted at a threshold of energy availability in regularly menstruating women. J. Clin. Endocrinol. Metab., 88(1): 297-311.

16. Lykkesfeldt J., Poulsen H.E. (2010) Is vitamin C supplementation beneficial? Lessons learned from randomised controlled trials. Br. J. Nutr., 103: 1251-1259.

17. McClung J.P., Gaffney-Stomberg E., Lee J.J. (2014) Female athletes: A population at risk of vitamin and mineral deficiencies affecting health and performance. J. Trace. Elem. Med. Bio., 28(4): 388-392.

18. Mountjoy M., Sundgot-Borgen J., Burke L., Carter S., Constantini N., Lebrun C., Meyer N., Sherman R., Steffen K., Budgett R., Ljungqvist A. (2015) Authors' 2015 additions to the IOC consensus statement: Relative Energy Deficiency In Sport (RED-S). Br. J. Sport Med., 49(7): 417-420.

19. Nelson E.M., Rejeski W.J., Blair N.S., Duncan P.W., Judge J.O., King A.C., Macera C.A., Castaneda-Sceppa C. (2007) Physical activity and public health in older adults recommendation from the American College of Sports Medicine and the American Heart Association. Med. Sci. Sports Exerc., 39(8): 1435-1445.

20. Nieman D.C., Henson D.A., McAnulty S.R., McAnulty L., Swick N.S., Utter A.C., Vinci D.M., Opiela S.J., Morrow J.D. (2002) Influence of vitamin C supplementation on oxidative and immune changes after an ultramarathon. J. Appl. Physiol., 92(5): 1970-1977.

21. Palacin-Arce A., Monteagudo C., Beas-Jimenez J. de C., Olea-Serrano F., Mariscal-Arcas M. (2015) Proposal of a Nutritional Quality Index (NQI) to evaluate the nutritional supplementation of sportspeople. PLoS One, 10(5)

22. Pilis K., Michalski C., Zych M., Pilis A., Jelonek J., Kaczmarzyk A., Pilis W. (2014) A nutritional evaluation of dietary behaviour in various professional sports. Rocz. Panstw. Zakl. Hig., 65(3): 227-234.

23. Pingitore A., Lima G.P., Mastorci F., Quinones A., Iervasi G., Vassalle C. (2015) Exercise and oxidative stress: potential effects of antioxidant dietary strategies in sports. Nutrition, 31(7-8): 916-922.

24. Potgieter S. (2013) Sport nutrition: A review of the latest guidelines for exercise and sport nutrition form the American College of Sport Nutrition, the International Olympic Committee and the International Society for Sports Nutrition. S. Afr. J. Clin. Nutr., 26: 6-16.

25. Rossow L.M., Fukuda D.H., Fahs C.A., Loenneke J.P., Stout J.R. (2013) Natural bodybuilding competition preparation and recovery: a 12-month case study. Int. J. Sports Physiol. Perform., 8(5): 582-592.

26. Rönn R.E., Guibentif C., Saxena S., Woods N.-B. (2017) Reactive Oxygen Species Impair The Function Of CD90 ${ }^{+}$ Hematopoietic Progenitors Generated From Human Pluripotent Stem Cells. Stem Cells, 35(1): 197-206.

27. Sachech M.J., Decker E.A., Clarkson P.M. (2000) The effect of diet on vitamin $\mathrm{E}$ intake and oxidative stress 
in response to acute exercise in female athletes. Eur. $J$. Appl. Physiol., 83(1): 40-46.

28. Sakano N., Wang D-H., Takahashi N., Wang B., Sauriasari R., Kanbara S., Sato Y., Takigawa T., Takaki J., Ogino K. (2009) Oxidative stress biomarkers and lifestyles in Japanese healthy people. J. Clin. Biochem. Nutr., 44(2): 185-195.

29. Schieber M., Chandel N.S. (2014) ROS function in redox signaling and oxidative stress. Curr. Biol., 24(10): 453-462.

30. Shmarakov I.O., Borschovetska V.L., Marchenko M.M., Blaner W.S. (2014) Retinoids modulate thioacetamide-induced acute hepatotoxicity. Toxicol. Sci., 139(2): 284-292.

31. Sies H. (2015) Oxidative stress: a concept in redox biology and medicine. Redox Biol., 4: 180-183.

32. Slater G., Phillips S. (2011) Nutrition guidelines for strength sports: sprinting, weightlifting, throwing events and bodybuilding. J. Sports Sci., 29(1): 67-77.

33. Slater J., Brown R., McLay-Cooke R., Black K. (2017) Low energy availability in exercising women: Historical perspectives and future directions. Sports Med., 47(2): 207-220.

34. Szponar L., Wolnicka K., Rychlik E. (2000) Album fotografii produktów i potraw. Warszawa: Instytut Żywności i Żywienia.

35. Tenforde S.A., Barrack T.M., Nattiv A., Fredericson M. (2016) Parallels with the Female Athlete Triad in male athletes. Sports Med., 46(2): 171-182.

36. Teshima K., Imamura H., Yoshimura Y., Nishimura S., Miyamoto N., Yamauchi Y., Hori H., Moriwaki C.,
Shirota T. (2002) Nutrient intake of highly competitive male and female collegiate karate players. J. Physiol. Anthropol. Appl. Human Sci., 21(4): 205-211.

37. Thomas D.R. (2006) Vitamins aging, health and longevity. Clin. Interv. Aging, 1(1): 81-91.

38. Thomas D.T., Erdman K.A., Burke L.M. (2016) Position of the Academy of Nutrition and Dietetics, Dietitians of Canada, and the American College of Sports Medicine: Nutrition and Athletic Performance. J. Acad Nutr. Diet., 116(3): 501-528.

39. Thomas L.D.K., Elinder C-G., Tiselius H-G., (2013) Ascorbic Acid Supplements and Kidney Stone Incidence among Men: A Prospective Study. JAMA Intern. Med., 173(5): 386-388.

40. Ye W., Zhu S., Liao C., et al. Xiao J., Wu Q., Lin Z., Chen J. (2017) Advanced oxidation protein products induce apoptosis of human chondrocyte through reactive oxygen species-mediated mitochondrial dysfunction and endoplasmic reticulum stress pathways. Fundam. Clin. Pharmacol., 31(1): 64-74.

41. Zorov D.B, Juhaszova M., Sollott S.J. (2014) Mitochondrial reactive oxygen species (ROS) and ROS-induced ROS release. Physiol. Rev., 94(3): 909-950.

\section{Received 23.01.2020 \\ Accepted 28.05.2020}

(c) University of Physical Education, Warsaw, Poland 